\title{
Adsorption and Reduction of NO on Tin(IV) Oxide Catalysts
}

\author{
F. Solymosi and J. Kiss \\ Gas Kinetics Research Group, The University, Szeged, Hungary
}

Received November 4, 1974; revised July 11, 1975

\begin{abstract}
Rates for NO chemisorption were measured on different samples of $\mathrm{SnO}_{2}$ in the temperature range $25-150^{\circ} \mathrm{C}$. Kinetic measurements revealed that the extent and the rate of NO adsorption on different surfaces increase in the order $\mathrm{SnO}_{2 \text { (oxddized) }} \ll \mathrm{SnO}_{2 \text { (actlvated) }}<\mathrm{SnO}_{2 \text { (reduced). It was }}$ found that preadsorbed NO promotes the adsorption of $\mathrm{CO}$, which was attributed to the formation of a surface isocyanate complex. Electrical conductivity measurements during NO adsorption revealed that both negatively and positively adsorbed species are present on activated surfaces.

The catalytic reduction of $\mathrm{NO}$ with $\mathrm{CO}$ on $\mathrm{SnO}_{2}$ proceeded with reproducible rates only above $360^{\circ} \mathrm{C}$. The reaction was of zero order with respect to $\mathrm{CO}$ and first order with respect to NO. The value of the activation energy is $36.6 \mathrm{kcal} / \mathrm{mole}$. It was found that the catalytic reaction takes place on a weakly reduced surface. It is postulated that the reduced centers play an important role in the activation of NO, and NO dissociates upon adsorption. A possible mechanism of the catalytic reduction of NO is discussed.
\end{abstract}

\section{INTRODUCTION}

Although studies of the catalytic chemistry of NO have multiplied considerably in recent years, relatively little is known about the interaction of nitric oxide with metal oxide surfaces, and especially about the mechanism of the catalytic reactions between nitric oxide and different fuels $(1,2)$. In the case of the NO-CO reaction the chromium-based catalysts (chromium(III) oxide, copper(II) chromite) were found to be among the most active substances. As it appeared (3) that the reduction and oxidation of chromium plays a significant role in the catalytic reduction of nitric oxide, our attention turned to catalyst systems in which the reductionand oxidation of chromium is especially favored. A prominent catalyst in this respect is tin(IV) oxide containing a small amount of chromium(III) oxide. Investiga- tion of the properties of $\mathrm{SnO}_{2}-\mathrm{Cr}_{2} \mathrm{O}_{3}$ catalysts revealed that during its incorporation into $\mathrm{SnO}_{2}$ in air a part of the chromium is converted to a higher oxidation state and stabilized in the surface layer of the $n$-type $\mathrm{SnO}_{2}(4-6)$. A noteworthy feature of chromium in the surface layer of $\mathrm{SnO}_{2}$ is that after its reduction with fuels it can easily be reoxidized, even at low temperatures.

In a preliminary communication we showed that $\mathrm{SnO}_{2}$ containing a small amount of $\mathrm{Cr}_{2} \mathrm{O}_{3}$ is a very active catalyst for the reduction of $\mathrm{NO}$ with $\mathrm{CO}, \mathrm{H}_{2}$, and $\mathrm{C}_{2} \mathrm{H}_{4}$, even at low temperature ( 7$)$.

In the present paper we report on the interaction of $\mathrm{NO}$ with $\mathrm{SnO}_{2}$ surfaces and the reduction of $\mathrm{NO}$ with $\mathrm{CO}$ on this oxide. A subsequent paper will deal with the effects on these processes of using $\mathrm{SnO}_{2}$ doped with chromium. 


\section{EXPERIMENTAL METHODS}

\section{Materials}

$\mathrm{SnO}_{2}$ was obtained by the action of $\mathrm{HNO}_{3}$ on metallic $\mathrm{Sn}$. It was dried at $120^{\circ} \mathrm{C}$, and heated at $350^{\circ} \mathrm{C}$ for $3 \mathrm{hr}$ and at $500^{\circ} \mathrm{C}$ for $5 \mathrm{hr}$. Final sintering was performed at $900^{\circ} \mathrm{C}$ for $5 \mathrm{hr}$ in air. The surface area of the $\mathrm{SnO}_{2}$ sample used was $5.8 \mathrm{~m}^{2} / \mathrm{g}$. Nitric oxide (Matheson Ltd.) was of commercial purity (99\%). It was purified by bulb-to-bulb distillation before use. The mass spectrum did not show the presence of $\mathrm{NO}_{2}$ or $\mathrm{N}_{2} \mathrm{O}_{3}$. Carbon monoxide was prepared in the laboratory by reacting formic acid with sulphuric acid at $83^{\circ} \mathrm{C}$.

For the catalytic studies, small pellets (1.5 $\mathrm{mm}$ in diameter and $1.5 \mathrm{~mm}$ long) were made. A fixed amount of catalyst (1.5 g, 8-10 small pellets) was used in every experiment.

Three different samples of catalyst have been used: (i) $\mathrm{SnO}_{2}$ activated in vacuum at $400^{\circ} \mathrm{C}$ for $60 \mathrm{~min}$, (ii) $\mathrm{SnO}_{2}$ partially reduced with $\mathrm{CO}$ at $400^{\circ} \mathrm{C}$ for $60 \mathrm{~min}$, (iii) $\mathrm{SnO}_{2}$ oxidized with $\mathrm{O}_{2}$ at $200^{\circ} \mathrm{C}$ for $60 \mathrm{~min}$.

\section{Apparatus}

For the kinetic investigations a closed circulation system (volume $277 \mathrm{ml}$ ) was used. The reaction was followed by measuring the pressure of the reacting gases. For analysis of the reaction products an A.E.I. MS-10 mass spectrometer was connected to the reactor.

Conductivity measurements during adsorption and catalytic reaction were performed in the same reactor, using pellets $8 \mathrm{~mm}$ in diameter and 6-7 $\mathrm{mm}$ long. An ac bridge was used for these measurements. Specific surface areas were calculated from the adsorption of nitrogen at liquid nitrogen temperature.

Adsorption measurements were carried out in a Sartorius microbalance.

\section{RESULTS}

\section{Adsorption of $\mathrm{NO}$}

A charactcristic feature of the adsorption of $\mathrm{NO}$ on diamagnetic oxides is its extreme slowness. On aluminium oxides, for instance, 100 days are required to achieve an adsorption equilibrium $(8,9)$. In spite of the low heat of adsorption, Solbakken and Reyerson (8) came to the conclusion that the adsorption of $\mathrm{NO}$ on $\mathrm{Al}_{2} \mathrm{O}_{3}$ is a chemisorption process. Magnetic data showed that NO loses its paramagnetism when adsorbed; its odd electron is thus paired with an electron from the alumina gel surface. The adsorption of $\mathrm{NO}$ on transition metal oxides $\left(\mathrm{Cr}_{2} \mathrm{O}_{3}, \mathrm{NiO}\right.$, and $\left.\mathrm{CuO}\right)$ has been studied recently by Shelef et al. (10-13).

a. Kinetics of adsorption. The primary aim of our adsorption studies was to compare the rate of adsorption of NO on different $\mathrm{SnO}_{2}$ surfaces.

The adsorption of $\mathrm{NO}$ on $\mathrm{SnO}_{2}$ is very slow, in spite of the fact that there is no experimental evidence for a substantial energy of activation. It may be concluded that the adsorption is associated with a very small preexponential factor.

Reversible adsorption was observed only on an oxidized surface. On an activated surface the adsorption was partly irreversible. In the case of the reduced surface the extent of the irreversibility (i.e., the relative amount of NO which, according to gravimetric measurements, is not desorbed at the same temperature) was higher. On an activated surface at adsorption equilibrium, at $105^{\circ} \mathrm{C}$, after $2 \mathrm{hr}$ of evacuation, $25 \%$ of the adsorbed NO remained on the surface. On a reduced surface this value was $45 \%$.

The reversibly adsorbed fraction of $N O$ on all three surfaces desorbed as NO at $25-50^{\circ} \mathrm{C}$. Above $100^{\circ} \mathrm{C}$ the desorbing gases from the activated surface contained $\mathrm{N}_{2}$ and $\mathrm{N}_{2} \mathrm{O}$, too. In the case of reduced 


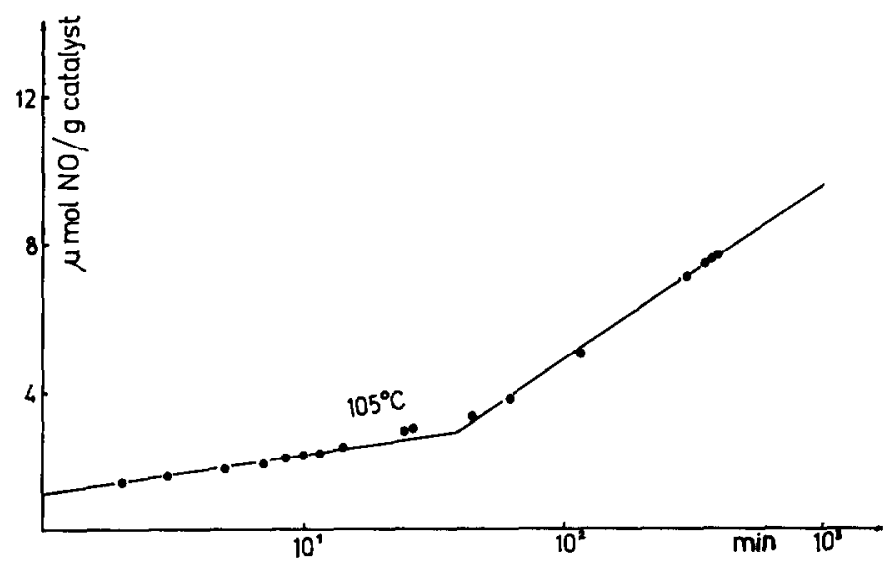

Fia. 1. Elovich plots in integrated form for $\mathrm{NO}$ adsorption on activated $\mathrm{SnO}_{2}$ at $105^{\circ} \mathrm{C}$ and 10 Torr.

surface the amount of $\mathrm{N}_{2} \mathrm{O}$ was smaller, whereas that of the $\mathrm{N}_{2}$ was larger.

The chemisorption kinetics of NO were followed at 10 Torr at $25-150^{\circ} \mathrm{C}$. The experimental results were evaluated with the integrated form of the Elovich equation

$$
q=(2.3 / \alpha) \log \left(t+t_{0}\right)-(2.3 / \alpha) \log t_{0},
$$

where $t_{0}=1 / a \alpha$ is an integration constant. Since $t_{0} \ll t$, the above equation can be reduced to

$$
q=(2.3 / \alpha) \log t-(2.3 / \alpha) \log t_{0}
$$

The Elovich plots consist of two linear segments with a distinct break between them (Fig. 1). A possible explanation of the break is that two distinct populations of adsorption sites exist on the surface.
The characteristic data of these plots are given in Table 1 . The instantaneous adsorption of NO increases with the temperature. $\alpha_{1}$ decreases rapidly, and $\alpha_{2}$ slightly with $T$; accordingly, the temperature coefficient of the adsorption is positive.

On partially reduced $\mathrm{SnO}_{2}$ the instantaneous uptake of NO was markedly larger than that on an unreduced sample, and also increased with increase of the temperature. The Elovich plots were of the same character as in the case of activated $\mathrm{SnO}_{2}$. The coefficient $\alpha_{1}$ was much smaller than that on activated $\mathrm{SnO}_{2}$, indicating that the rate of adsorption of $\mathrm{NO}$ was higher. Its value similarly decreased with increase of the temperature. No significant difference was found between the values of

TABLE 1

\begin{tabular}{|c|c|c|c|c|c|c|c|c|}
\hline \multirow[b]{2}{*}{$\begin{array}{c}T \\
\left({ }^{\circ} \mathrm{C}\right)\end{array}$} & \multicolumn{4}{|c|}{ Activated $\mathrm{SnO}_{2}$} & \multicolumn{4}{|c|}{ Reduced $\mathrm{SnO}_{2}$} \\
\hline & $\begin{array}{c}q_{0}^{a} \\
(\mu \mathrm{mole} / \mathrm{g})\end{array}$ & $\begin{array}{l}\alpha_{1} \\
{[\mu \mathrm{m}}\end{array}$ & $\begin{array}{r}\alpha_{2} \\
g]^{-1}\end{array}$ & $\theta$ & $\begin{array}{c}q_{0} \\
(\mu \mathrm{mole} / \mathrm{g})\end{array}$ & $\begin{array}{l}\alpha_{1} \\
{[\mu \mathrm{m}}\end{array}$ & $\begin{array}{r}\alpha_{2} \\
g]^{-1}\end{array}$ & $\theta$ \\
\hline 25 & 0.8 & 4.45 & 0.35 & 0.036 & 1.9 & 4.1 & 0.13 & 0.042 \\
\hline 50 & 0.91 & 3.45 & 0.47 & 0.053 & 2.35 & 1.3 & 0.14 & 0.081 \\
\hline 105 & 1 & 2.1 & 0.46 & 0.057 & 3.15 & 0.76 & 0.15 & 0.115 \\
\hline 150 & 1.16 & 1.6 & 0.46 & 0.047 & & & & \\
\hline
\end{tabular}

Characteristic Data of Elovich Equation

a $q_{0}=$ the amount of instantaneous adsorption. 
$\alpha_{2}$. Attempts were made to measure the adsorption of $\mathrm{NO}$ on an oxidized surface $\left(\mathrm{SnO}_{2}\right.$ treated with $\mathrm{O}_{2}$ at $200^{\circ} \mathrm{C}$ for 60 min and the system then evacuated for 5 min and cooled down to the temperature of adsorption). The adsorption of NO on this surface was extremely slight and slow.

For comparison of the adsorption rates on different $\mathrm{SnO}_{2}$ surfaces, Table 2 shows actual rates measured at a constant coverage, $\theta=0.065$. Measurements were made to determine the degree of irreversibility of $\mathrm{NO}$ adsorption in the first and second stages of the Elovich plots. On activated surface at $105^{\circ} \mathrm{C}, 85 \%$ of the adsorbate before the break in the Elovich plots is strongly held on the surface, while in the second stage the corresponding value is less than $30 \%$.

b. Coadsorption and promoted adsorption. The coadsorption of $\mathrm{NO}+\mathrm{CO}$ has been studied at $100^{\circ} \mathrm{C}$ in the case of $\mathrm{SnO}_{2}$ activated in vacuum at $400^{\circ} \mathrm{C}$. Using a mixture of $\mathrm{NO}+\mathrm{CO}(1: 1)$, the extent of adsorption was ten times larger than the sum for the separately adsorbed gases. Preadsorbed nitric oxide was found to promote both the rate and the extent of $\mathrm{CO}$ adsorption (Fig. 2). The ratio of the adsorbed $\mathrm{NO}$ and $\mathrm{CO}$ promoted approaches unity, pointing to the existence of a surface complex apparently containing equal numbers of moles of $\mathrm{NO}$ and $\mathrm{CO}$. However, when the adsorbed amount of NO exceeded a certain value $(1.1 \mu \mathrm{mole} / \mathrm{g}, \theta=0.03$,

\section{TABLE 2}

Rates of NO Adsorption on $\mathrm{SnO}_{2}$ Samples at $\theta=0.065$

\begin{tabular}{rccc}
$\begin{array}{c}T \\
\left({ }^{\circ} \mathrm{C}\right)\end{array}$ & $\begin{array}{c}\text { Oxidized } \\
(\mu \mathrm{mole} / \mathrm{g} \\
\mathrm{min})\end{array}$ & $\begin{array}{c}\text { Activated } \\
(\mu \mathrm{mole} / \mathrm{g} \\
\mathrm{min})\end{array}$ & $\begin{array}{c}\text { Reduced } \\
(\mu \mathrm{mole} / \mathrm{g} \\
\mathrm{min})\end{array}$ \\
\hline 25 & & 0.0516 & 0.0036 \\
50 & & 0.266 & 0.35 \\
100 & 0.0070 & 0.730 & 3.28 \\
150 & & 1.300 & \\
\hline
\end{tabular}

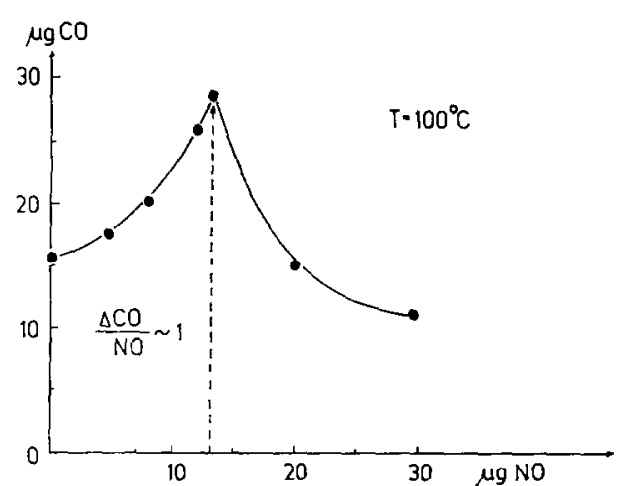

FIG. 2. The adsorption of $\mathrm{CO}$ on activated $\mathrm{SnO}_{2}$ at $100^{\circ} \mathrm{C}$ as a function of the amount of preadsorbed NO.

in this case), the adsorption of $\mathrm{CO}$ decreased and finally the promotion changed into inhibition. This limiting value is very nearly the same as the amount of NO strongly adsorbed under similar experimental conditions. During the study of coadsorption and promoted adsorption at $100^{\circ} \mathrm{C}$ we did not detect significant quantities of $\mathrm{CO}_{2}$ and other reaction products by mass spectrometric analysis. It is important to note that (i) adsorbed oxygen does not promote the adsorption of $\mathrm{CO}$ even on activated surface, (ii) preadsorbed $\mathrm{CO}$ does not enhance the adsorption of NO, and (iii) no promoted adsorption of $\mathrm{CO}$ occurred at $100^{\circ} \mathrm{C}$, on oxidized surfaces.

\section{Electrical Conductivity Measurements during the Adsorption of $\mathrm{NO}$ and $\mathrm{CO}$}

Some electrical resistivity measurements have been carried out during the adsorption of $\mathrm{NO}$ in order to characterize the nature of the electronic interaction between $\mathrm{NO}$ and $n$-type. $\mathrm{SnO}_{2}$. The low ionization potential of $\mathrm{NO}, 9.5 \mathrm{~V}$, makes possible the conversion of the nitric oxide molecule to the nitrosonium ion, $\mathrm{NO}^{+}$. $\mathrm{NO}$ can also easily take up an electron to be converted to a nitrosyl ion $\mathrm{NO}^{-}$. The lower limit to the electron affinity of gaseous $\mathrm{NO}$ is $0.65 \mathrm{eV}$ (14). Figure 3 shows that the adsorption of NO increases the electrical resistivity of acti- 


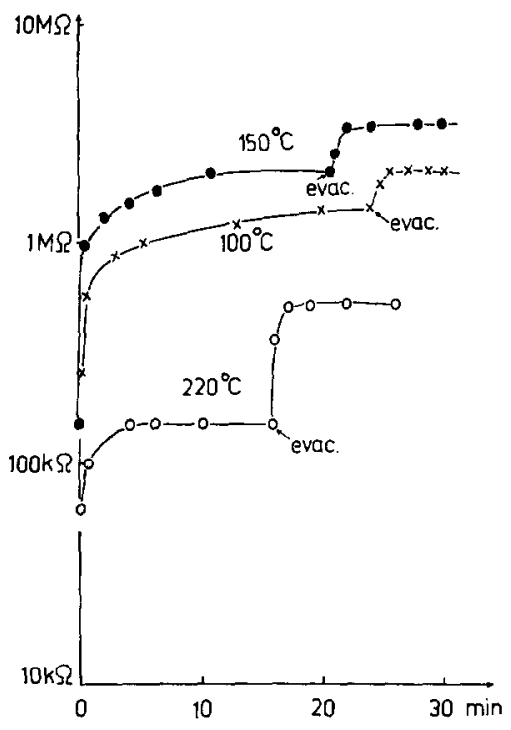

Fra. 3. The effect of $\mathrm{NO}$ and subsequent evacuation on the electrical resistivity of activated $\mathrm{SnO}_{2}$ at different temperatures.

vated $\mathrm{SnO}_{2}$, which can be explained by the formation of negatively charged adsorbed species, $\mathrm{NO}^{-}$and/or $\mathrm{O}^{-}$, according to the equations

$$
\begin{aligned}
\mathrm{NO}_{(\mathrm{g})}+e_{0}^{-} & =\mathrm{NO}^{-}{ }_{\text {(chem) }}, \\
2 \mathrm{NO}_{(\mathrm{g})}+e_{0}^{-} & =\mathrm{N}_{2} \mathrm{O}+\mathrm{O}^{-} \text {(chem). }
\end{aligned}
$$

On evacuation of the NO from the reaction cell at the same temperature the electrical resistivity of the $\mathrm{SnO}_{2}$ further increased to a small extent. This behavior indicates that, besides the above modes of adsorption, a part of the NO is chemisorbed by giving its unpaired electron to the oxide surface forming an apparently positively chemisorbed ion

$$
\mathrm{NO}_{(\mathrm{g})}=\mathrm{NO}^{+}{ }_{(\mathrm{ohem})}+e_{0}^{-} .
$$

This kind of NO adsorption partly compensated the result of the electron acceptor adsorptions [Eqs. (1) and (2)]. This adsorption is much weaker than the former ones, so that on evacuation of the sample $\mathrm{NO}$ from $\mathrm{NO}^{+}$desorbs from the surface

$$
\mathrm{NO}^{+}{ }_{\text {(chem })}+e_{0^{-}}^{-}=\mathrm{NO}_{(\mathbf{g})},
$$

and as a result the electric resistivity of
$\mathrm{SnO}_{2}$ increases. Qualitatively the same behavior was found at higher temperatures, up to $300^{\circ} \mathrm{C}$. Above $300^{\circ} \mathrm{C}$ the formation of $\mathrm{NO}^{+}{ }_{(\mathrm{chem})}$, if any, was not indicated by electrical conductivity measurements.

When NO was admitted to the catalyst in doses (25 Torr at a time), the effect of the second dose differed from that of the first. The extent of the first resistivity increase was smaller than in the case of the first NO dose, whereas that of second one was larger. On admission of the third dose the resistivity of the sample first decreased. On evacuation, however, the resistivity became higher than it had been before the third dose, indicating that both types of chemisorption processes had occurred on admission of $\mathrm{NO}$, but that the effect of $\mathrm{NO}^{+}$formation exceeded that due to $\mathrm{NO}^{-}$ and $\mathrm{O}^{-}$. After a further dose the resistivity of the sample again decreased, but on pumping off the gases the resistivity of the $\mathrm{SnO}_{2}$ scarcely exceeded the value measured before this dose. It seems very likely that here the formation of negatively charged adsorbed species was very low compared to the previous cases and to the formation of $\mathrm{NO}^{+}$(Fig. 4).

This series of experiments convincingly shows that the activated tin dioxide surface has only a limited number of active sites available for the formation of negatively charged adsorbed species. When $\mathrm{SnO}_{2}$ was not activated at $400^{\circ} \mathrm{C}$ in vacuum, but merely evacuated at the adsorption temperature $\left(25-150^{\circ} \mathrm{C}\right)$, its resistivity decreased to only a small extent on introduction of NO. From this observation it can be inferred that $\mathrm{SnO}_{2}$ is partially reduced during the activation process and that the reduced centers are responsible for the formation of $\mathrm{NO}^{-}$and/or $\mathrm{O}^{-}$.

Some preliminary mass-spectrometric analyses have been conducted on the composition of the gases desorbed from activated $\mathrm{SnO}_{2}$ pellets. In this case $\mathrm{NO}$ was adsorbed on $\mathrm{SnO}_{2}$ at $100^{\circ} \mathrm{C}$ for $60 \mathrm{~min}$ and the gaseous NO and the weakly held NO 


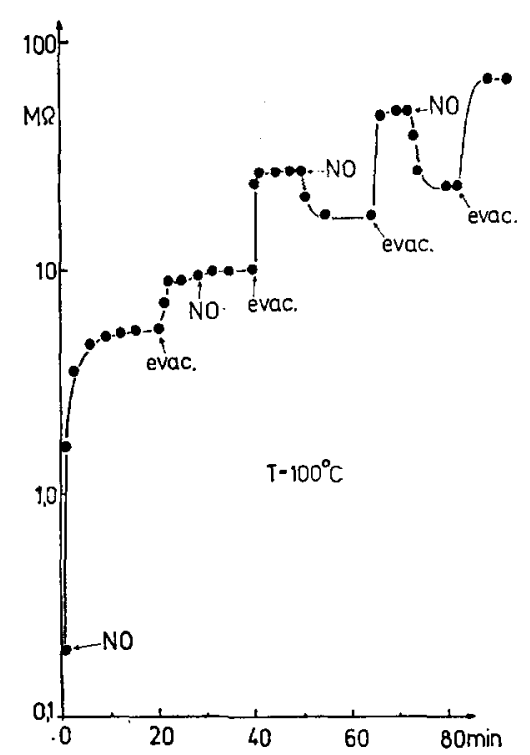

FIG, 4. The effect of NO doses (25 Torr) and subsequent evacuations on the electrical resistivity of activated $\mathrm{SnO}_{2}$ at $100^{\circ} \mathrm{C}$.

was pumped off for $5 \mathrm{~min}$, and the sample was then kept at the same temperature for $60 \mathrm{~min}$. In the gases desorbing at $100^{\circ}$ we found $\mathrm{NO}(30 \%), \mathrm{N}_{2}(40 \%)$, and $\mathrm{N}_{2} \mathrm{O}$ $(28 \%)$. On heating the sample in vacuum to $180^{\circ} \mathrm{C}$ the desorption products contained only $\mathrm{NO}(80 \%)$ and $\mathrm{N}_{2}(20 \%)$, whereas at $240^{\circ} \mathrm{C}$ it consisted of $\mathrm{NO}(36 \%), \mathrm{N}_{2}$ $(53 \%)$, and $\mathrm{O}_{2}(11 \%)$. On further heating of the sample to $320^{\circ} \mathrm{C}$ and then to $360^{\circ} \mathrm{C}$ only the partial pressures of $\mathrm{N}_{2}$ and $\mathrm{O}_{2}$ were increased. The molar ratio of $\mathrm{N}_{2}$ and $\mathrm{O}_{2}$ was 3 at $320^{\circ} \mathrm{C}$ and 1 at $360^{\circ} \mathrm{C}$.

From these results it may be inferred that a part of the NO is adsorbed dissociatively on the activated surface, the extent of dissociation increasing with the temperature. Although the species most strongly held on activated $\mathrm{SnO}_{2}$ is oxygen, very probably in the form of $\mathrm{O}^{-}$ions, on the basis of these experiments the possibility cannot be excluded that the transient formation of $\mathrm{NO}^{-}$ions also contributes to the electrical resistivity increase of $\mathrm{SnO}_{2}$.

When a 1:1 mixture of $\mathrm{NO}+\mathrm{CO}$ was admitted to the activated sample at $100^{\circ} \mathrm{C}$, the electrical resistivity again in- creased, and to a somewhat larger extent than in the case of $\mathrm{NO}$, in spite of the fact that $\mathrm{CO}$ along decreased the resistivity of $\mathrm{SnO}_{2}$.

$$
\mathrm{CO}_{(\mathrm{g})}=\mathrm{CO}^{+}{ }_{(\mathrm{chem})}+e_{0}^{-} .
$$

On evacuation the resistivity further increased. This is shown in Fig. 5. In the range $150-250^{\circ} \mathrm{C}$ the situation was somewhat different; the resistivity first increased, and then decreased, slowly approaching a steady-state value. Above $250^{\circ} \mathrm{C}$ the initial resistivity increase was not exhibited. In the temperature range of the catalytic reaction, $390-440^{\circ} \mathrm{C}$, the electrical resistivity of $\mathrm{SnO}_{2}$ dcereased by onc order of magnitude, and remained at this level until the very end of the catalytic reaction. The same behavior was observed with a slight excess of $\mathrm{NO}$ ( $\mathrm{NO}$ :CO mole ratio 2.5:1). This indicates that at this temperature the reducing effect of $\mathrm{CO}$ is dominant and the catalyst is in a partially reduced state in the course of the catalytic reduction. The same types of resistivity vs time curves were obtained in the pres-

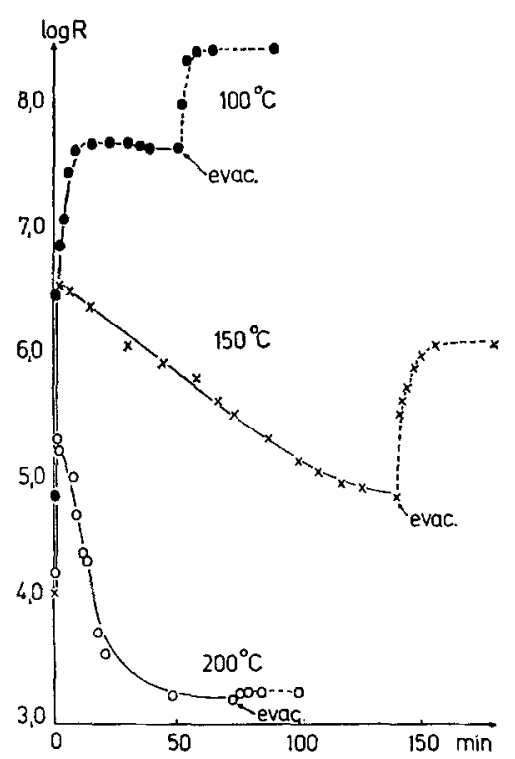

Fig. 5. The effect of NO + CO mixture $(1: 1)$ on the electrical resistivity of activated $\mathrm{SnO}_{2}$ at different temperatures. 


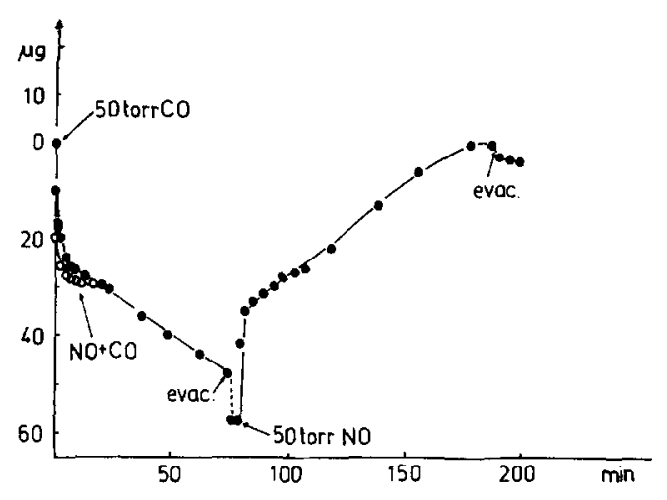

Fig. 6. The reduction and reoxidation of $\mathrm{SnO}_{2}$ catalyst with $\mathrm{CO}, \mathrm{NO}-\mathrm{CO}(1: 1)$ and $\mathrm{NO}$ at $418^{\circ} \mathrm{C}$. The change in the weight of $\mathrm{SnO}_{2}$ is plotted on the ordinate. The amount of $\mathrm{SnO}_{2}$ was $0.4 \mathrm{~g}$.

ence of $\mathrm{CO}$ alone, the initial resistivity increase not, occurring.

\section{Reduction and Reoxidation of Catalysts}

Next a study was made of the reduction and reoxidation of catalyst samples at the temperatures of the catalytic reaction in the Sartorius microbalance. When CO was admitted to an activated sample at $400^{\circ} \mathrm{C}$ there was an initially rapid, and then a slower, weight decrease (Fig. 6). The rate of the initial stage was practically independent of temperature. The reoxidation of the reduced sample with $\mathrm{NO}$ also proceeds in two steps. It is to be noted that the oxidation of the reduced sample took place within a matter of moments on the action of an equivalent amount of oxygen, even if the temperature was decreased by almost $200^{\circ} \mathrm{C}$. Using $1: 1$ mixture of $\mathrm{NO}$ and $\mathrm{CO}$ at the same temperature, the initial rapid weight decrease observed earlier on the introduction of $\mathrm{CO}$ alone was found here too, and its extent was practically the same as that in the absence of NO (Fig. 6). In the case of a $\mathrm{CO}$ excess, a further weight decrease (reduction) occurred with the consumption of the NO, while on the use of excess NO the catalyst weight slowly increased with the reaction of the $\mathrm{CO}$ until it attained the original weight of the starting material.

\section{Kinetic Measurements}

The reduction of NO by $\mathrm{CO}$ proceeded with reproducible rates and conversions in vacuum only above $360^{\circ} \mathrm{C}$. After a slight initial decrease, the activity of the catalyst remained constant. The reduction of nitric oxide to nitrogen was practically complete. The transient formation of $\mathrm{N}_{2} \mathrm{O}$ was observed during the experiments, its amount, however, always remaining below $2 \%$. The rate of the reaction was not influenced by the reaction products $\left(\mathrm{CO}_{2}, \mathrm{~N}_{2}\right)$ at $360-$ $440^{\circ} \mathrm{C}$.

The efficiency of $\mathrm{SnO}_{2}$ was also tested at lower temperatures $\left(150-360^{\circ} \mathrm{C}\right)$, where the initial rate and the conversion of the NO reduction depended sensitively on the pretreatment of the $\mathrm{SnO}_{2}$. Catalytic reaction on $\mathrm{SnO}_{2}$ activated at $400^{\circ} \mathrm{C}$ in vacuum was observed even at $155^{\circ} \mathrm{C}$. The conversion in the first run was $7.5 \%$. In the second run, however, the $\mathrm{SnO}_{2}$ was completely inactive. Similar behavior was experienced at higher temperatures up to $360^{\circ} \mathrm{C}$, with the difference that the initial rate and the conversion of the reduction were higher.

When the $\mathrm{SnO}_{2}$ was previously treated with $\mathrm{CO}$ at $400^{\circ} \mathrm{C}$ (reduced surface) the initial rate and the conversion of the catalytic reaction measured at $250-360^{\circ} \mathrm{C}$ were somewhat higher than for the activated catalysts. However, after treatment of the activated sample with $\mathrm{NO}$ or with $\mathrm{O}_{2}$ for $1 \mathrm{hr}$ at $155-360^{\circ} \mathrm{C}$, the initial activity of the catalyst measured at the same temperature was significantly reduced.

Detailed kinetic measurements were carried out at $390-440^{\circ} \mathrm{C}$ with a stoichiometric mixture of the reacting gases. The reaction was of zero order with respect to $\mathrm{CO}$, and first order with respect to NO (Fig. 7). The activation energy was 36.6 $\mathrm{kcal} / \mathrm{mole}$, and thus considerably larger than that of the $\mathrm{CO}-\mathrm{O}_{2}$ reaction (15). The same value was obtained with a CO-NO molar composition of 5:1. Kinetic data are given in Table 3. 


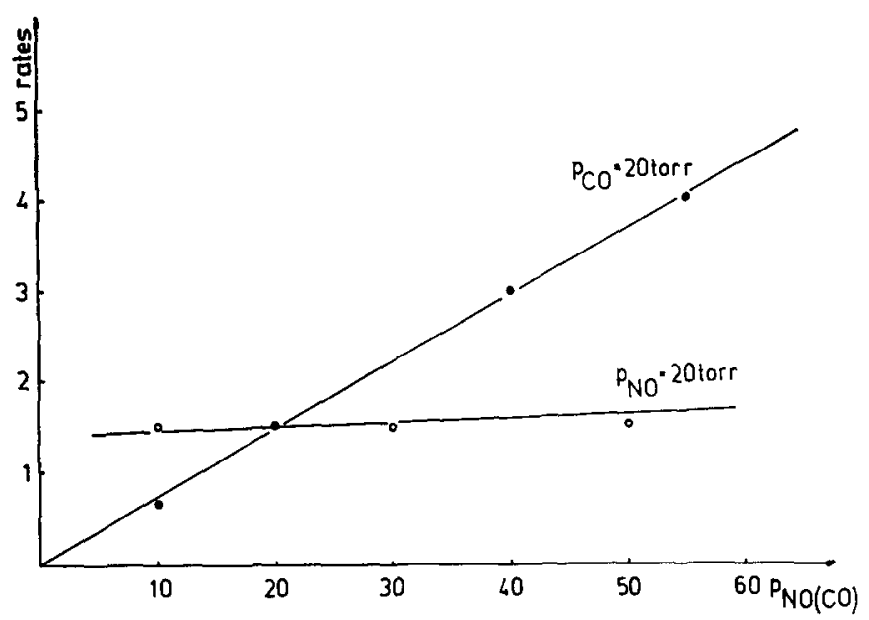

FIG. 7. The dependence of initial rates of $\mathrm{NO}-\mathrm{CO}$ reaction on $\mathrm{SnO}_{2}$ at $420^{\circ} \mathrm{C}$ as a function of partial pressure of $\mathrm{NO}$ and $\mathrm{CO}$, respectively.

\section{DISCUSSION}

Adsorption measurements revealed that the extent and the rate of NO adsorption on different surfaces increase in the order $\mathrm{SnO}_{2 \text { (oxidized) }} \ll \mathrm{SnO}_{2 \text { (activated) }}<\mathrm{SnO}_{2 \text { (reduced) }}$

The irreversibility of $\mathrm{NO}$ adsorption also increases in this order. This indicates that the reduced centers of the $\mathrm{SnO}_{2}$, very probably $\mathrm{Sn}^{3+}$ ions, play an important role in the adsorption and activation of the NO molecule. Mass-spectrometric analysis of the gases desorbed from the activated oxide indicated that NO dissociated upon adsorption, and as a result the catalyst surface became oxidized and inactivated.

From elcctrical resistivity measurements during the adsorption of NO it was concluded that both negatively and positively charged adsorbed species are present on the activated $\mathrm{SnO}_{2}$ surface.

Since the formation of $\mathrm{NO}^{+}$is accompanied by the strengthening of the $\mathrm{N}-\mathrm{O}$ bond, while the transfer of an electron to the antibonding orbital of the NO leads to the greatest weakening of the bond, it seems plausible to assume that the oxidation of the catalyst surface occurs as a result of the transient formation and dissociation of the $\mathrm{NO}^{-}$species.
It appears very likely that the presence of adsorbed nitrogen is responsible for the promoted adsorption of $\mathrm{CO}$, possibly through the formation of a surface isocyanate complex

$$
\mathrm{M}-\mathrm{N}+\mathrm{CO}=\mathrm{M}^{+} \mathrm{NCO}^{-}
$$

(M represents the active surface site, $\mathrm{Sn}^{3+}$ ion).

It is possible that the enhanced electrical resistivity of $\mathrm{SnO}_{2}$ at $100^{\circ} \mathrm{C}$ in the presence of an NO-CO mixture, compared to the value obtained in $\mathrm{NO}$ or $\mathrm{CO}$ alone, is also a result of the formation of a surface isocyanate complex. Isocyanate species have

TABLE 3

Kinetic Data for the Catalytic Reduction of $\mathrm{NO}^{a}$

\begin{tabular}{cc}
\hline $\begin{array}{c}T \\
\left({ }^{\circ} \mathrm{C}\right)\end{array}$ & $\begin{array}{c}10^{-3} k_{\text {spec }} \\
\left(\mathrm{min}^{-1} \mathrm{~m}^{-2}\right)\end{array}$ \\
\hline 398 & 0.67 \\
405 & 1.1 \\
420 & 2.4 \\
420 & 2.4 \\
430 & 3.4 \\
440 & 4.5 \\
\hline
\end{tabular}

a $E=36.6 \mathrm{kcal} / \mathrm{mole}$; Frequency factor $=9.12$ $\times 10^{8} \min ^{-1} \mathrm{~m}^{-2}$. 
been detected by infrared spectroscopy during the reaction of $\mathrm{NO}$ with $\mathrm{CO}$ on the surface of noble metal catalysts (16) and also on supported $\mathrm{CuO}(17)$.

The fact that the extent of promoted adsorption exhibits a maximum as a function of the preadsorbed NO can be explained on the basis that only a limited number of active $\mathrm{Sn}^{3+}$ sites are available for the activation of the NO molecule and for the formation of adsorbed nitrogen. Measurements of the electrical resistivity of $\mathrm{SnO}_{2}$ when NO was admitted in doses support this conclusion. The decrease of the extent of promoted adsorption at higher concentrations of adsorbed NO indicates that the gaseous NO combines with the adsorbed nitrogen

$$
\mathrm{M}-\mathrm{N}+\mathrm{NO}=\mathrm{M}-\mathrm{N}-\mathrm{NO} \text {, }
$$

thereby reducing the possibility of formation of isocyanate species. The fact that at still higher concentrations of preadsorbed NO the promotion changed into inhibition means that in this case NO occupied the other adsorption sites, possibly the $\mathrm{Sn}^{4+}$ ions otherwise available for the adsorption of $\mathrm{CO}$

$$
\mathrm{M}^{+}+\mathrm{NO}=\mathrm{M}-\mathrm{NO}^{+}
$$

The observation that promoted adsorption of $\mathrm{CO}$ does not occur on an oxidized surface is in agreement with this picture.

From the study of the interaction of the reaction mixture with the catalyst during the catalytic process above $390^{\circ} \mathrm{C}$ by means of electrical conductivity and microgravimetric measurements, it appeared that the reduction of the $\mathrm{SnO}_{2}$ surface with $\mathrm{CO}$ is much faster than the reoxidation of the reduced centers with NO. In agreement with this the oxidation of $\mathrm{CO}$ with $\mathrm{NO}$ takes place on the weakly reduced $\mathrm{SnO}_{2}$. Taking into account all our results and observations the following elementary steps are suggested for the reduction of NO with
$\mathrm{CO}$ on $\mathrm{SnO}_{2}$ :

$$
\begin{aligned}
\mathrm{M}^{+} \mathrm{O}^{-}+\mathrm{CO} & \rightarrow \mathrm{M}+\mathrm{CO}_{2}, \\
\mathrm{M}+\mathrm{NO} & \rightleftharpoons \mathrm{M}^{+} \mathrm{NO}^{-}, \\
\mathrm{M}^{+} \mathrm{NO}^{-}+\mathrm{M} & \rightarrow \mathrm{M}-\mathrm{N}+\mathrm{M}^{+} \mathrm{O}^{-},
\end{aligned}
$$

or

$$
\begin{gathered}
\mathrm{M}+\mathrm{NO} \rightleftharpoons \mathrm{M}-\mathrm{NO} \\
\mathrm{M}-\mathrm{NO}+\mathrm{M} \rightarrow \mathrm{M}-\mathrm{N}+\mathrm{M}^{+} \mathrm{O}^{-}, \\
\mathrm{M}-\mathrm{N}+\mathrm{NO} \rightleftharpoons \mathrm{M}-\mathrm{NNO} \\
\mathrm{M}-\mathrm{NNO}+\mathrm{M} \rightarrow \mathrm{M}+\mathrm{N}_{2}+\mathrm{M}^{+} \mathrm{O}^{-} \\
\mathrm{M}^{+} \mathrm{O}^{-}+\mathrm{CO} \rightarrow \mathrm{M}+\mathrm{CO}_{2} \\
2 \mathrm{NO}+2 \mathrm{CO} \rightarrow \mathrm{N}_{2}+2 \mathrm{CO}_{2}
\end{gathered}
$$

The transient appearance of $\mathrm{N}_{2} \mathrm{O}$ in the gas phase is the result of the reaction

$$
\mathrm{M}-\mathrm{NNO} \rightleftharpoons \mathrm{M}+\mathrm{N}_{2} \mathrm{O} \text {. }
$$

The decomposition of $\mathrm{N}_{2} \mathrm{O}$ may occur in the reactions

$$
\begin{aligned}
& \mathrm{M}+\mathrm{N}_{2} \mathrm{O} \rightleftharpoons \mathrm{M}-\mathrm{ONN}, \\
& \mathrm{M}-\mathrm{ONN} \rightarrow \mathrm{M}^{+} \mathrm{O}^{-}+\mathrm{N}_{2} .
\end{aligned}
$$

An alternative to reactions (12)-(14) is that $\mathrm{CO}$ reacts with the adsorbed nitrogen atom and the reaction takes place through the formation of surface isocyanate complex

$$
\begin{aligned}
\mathrm{M}-\mathrm{N}+\mathrm{CO} & \rightleftharpoons \mathrm{M}^{+} \mathrm{NCO}^{-}, \\
\mathrm{M}^{+} \mathrm{NCO}^{-}+\mathrm{NO} & \rightarrow \mathrm{M}+\mathrm{N}_{2}+\mathrm{CO}_{2} .
\end{aligned}
$$

\section{REFERENCES}

1. Shelef, M., and Kummer, J. T., Chem. Eng. Prog. Symp. Ser. 67, 74 (1971).

2. Dwyer, F. G., Catal. Rev. 6, 261 (1972).

3. Otto, K., and Shelef, M., J. Catal. 12, 361 (1968).

4. Solymosi, F., and Bánsági, T., "Proceedings of the 2nd International Conference on Space Engineering," p. 145. Reidel, Dordrecht, Holland, 1970.

5. Solymosi, F., Hess, A., and Bozsó, F., Magy. Kem. Foly., 81, 81 (1975).

6. Solymosi, F., Kiss, J., and Bozsó, F., Paper presented at Euchem Conference on the Role of Catalysis in Problem of Pollution, Santander, July 13-15, 1973.

7. Solymosi, F., Kiss, J., J. Chem. Soc. Chem. Commun. 509 (1974). 
8. Solbakken, A., and Reyerson, L. H., J. Phys. Chem. 66, 365 (1962).

9. Solbakken, A., and Reyerson, L. H., J. Phys. Chem. 64, 1903 (1960).

10. Otto, K., and Shelef, M., J. Catal. 14, 226 (1969). 11. Shelef, M., and Otto, K., J. Calal. 18, 184 (1970).

12. Gandhi, M. S., and Shelef, M., J. Catal. 24, 241 (1972).
19. Gandhi, M. S., Shelef, M., J. Catal. 28, 1 (1973). 14. Stockdale, J. A. D., Compton, R. N., Hurst, G. S., and Reinhardt, P. W., J. Chem. Phys. 50, 2176 (1969).

15. Solymosi, F., and Kiss, J., to be published.

16. Unland, M. L., J. Catal. 31, 459 (1973).

17. London, J., and Bell, A. T., J. Catal. 31, 96 (1973). 